\title{
Jurnal

\section{PEMBERDAYAAN MASYARAKAT DALAM KESEHATAN IBU DAN ANAK SEBAGAI UPAYA MENINGKATKAN DERAJAT KESEHATAN}

\section{Community Empowerment in Maternal and Child Health as An Effort to Increase Health Degree}

\section{Eny Retna Ambarwati ${ }^{1}$, Niarna Lusi ${ }^{1}$, Rizham Maulidatun Nisa ${ }^{1}$, Rita Azca Azhari ${ }^{1}$, Riza Viky Krisnasari ${ }^{1}$}

\author{
AKBIDYO College of Health Sciences
}

\section{Riwayat artikel \\ Diajukan: 16 Agustus 2021 \\ Diterima: 16 September \\ 2021 \\ Penulis Korespondensi: \\ - Eny Retna Ambarwati \\ - AKBIDYO College of Health Sciences \\ e-mail: \\ enyretna@gmail.com}

\section{Kata Kunci:}

Community Empowerment, Maternal and Child Health, Health Degree

\begin{abstract}
Abstrak
Pendahuluan : Peningkatan status kesehatan masyarakat khususnya ibu dan anak dengan indikator menurunnya angka kematian ibu dan anak meningkatnya promosi kesehatan dan pemberdayaan masyarakat. Permasalahan yang diangkat sebagai program adalah masih banyak pasangan usia subur yang belum menggunakan kontrasepsi, rendahnya pengetahuan tentang deteksi dini kanker payudara, masih balita dengan pertumbuhan dan perkembangan menyimpang dan balita dengan gizi kurang. Tujuan: memberdayaan masyarakat melalui pendampingan pada ibu dan anak. Metode: Memberikan beberapa penyuluhan dan pemeriksaan yaitu penyuluhan berbagai macam alat kontrasepsi, penyuluhan deteksi dini kanker payudara, penimbangan balita, penyuluhan pentingnya gizi balita, pemeriksaan stimulasi deteksi dini pertumbungan perkembangan balita dan penimbangan balita. Hasil: Terdapat peningkatan sebesar $11,9 \%$, pada penyuluhan sadari terdapat peningkatan sebesar $19 \%$, pada kegiatan penimbangan balita terdapat peningkatan sebesar $14,3 \%$, pada pemeriksaan deteksi dini stimulasi pertumbuhan dan perkembangan terdapat peningkatan sebesar $100 \%$ sedangkan pada penyuluhan pentingnya gizi balita terdapat peningkatan sebesar $16,1 \%$. Pemberdayaan masyarakat pada ibu dan anak dapat meningkatan pengetahuan, sikap dan perilaku masyarakat dalam mengatasi permasalahan kesehatan kesehatan ibu dan anak sehingga dapat meningkatkan derajat kesehatan ibu dan anak. Kesimpulan: Pemberdayaan Masyarakat pada ibu dan anak dapat menjadi upaya strategis yang perlu terus dilanjutkan sehingga kampanye gerakan hidup sehat kepada masyarakat dapat terus berlanjut secara lebih masif dan sistemis
\end{abstract}

\section{Abstract}

Background: Improving the health status of the community, especially mothers and children with indicators of decreasing maternal and child mortality, increasing health promotion and community empowerment. The problems raised as a program are that there are still many couples of childbearing age who have not used contraception, lack of knowledge about early detection of breast cancer, still toddlers with deviant growth and development and toddlers with poor nutrition. Objective: is to empower the community through mentoring for mothers and children. Method: By providing several counseling and examinations, namely counseling on various types of contraception, counseling on early detection of breast cancer, weighing toddlers, counseling on the importance of toddler nutrition, stimulation checks for early detection of growth and development of toddlers and weighing toddlers. Results: there was an increase of $11.9 \%$, in awareness counseling there was an increase of 19\%, in weighing activities for toddlers there was an increase of $14.3 \%$, in the early detection examination of growth and development stimulation there was an increase of $100 \%$ while in counseling the importance of nutrition for toddlers, there was an increase of $16.1 \%$. Community empowerment for mothers and children can increase the knowledge, attitudes and behavior of the community in overcoming maternal and child health problems so as to improve the health status of mothers and children. Conclusion: Community empowerment for mothers and children can be a strategic effort that needs to be continued so that the campaign for the healthy living movement to the community can continue more massively and systematically. 


\section{PENDAHULUAN}

Perubahan paradigma sakit ke paradigma sehat merupakan bentuk perhatian masyarakat terhadap masalah kesehatan. Paradigma sakit merupakan upaya dengan menekankan pada aspek kuratif dan rehabilitatif yaitu untuk membuat orang sakit menjadi sehat sedangkan paradigma sehat merupakan upaya yang menekan pada pada aspek promotif dan preventif yaitu membuat orang sehat tetap sehat.

Paradigma masyarakat yang berubah terhadap kesehatan akan merubah pemeran dalam pencapaian kesehatan masyarakat, dengan tidak mengesampingkan peran pemerintah dan petugas kesehatan. Perubahan paradigma masyarakat menjadikan masyarakat sebagai pemeran utama dalam pencapaian derajat kesehatan. Gerakan pemberdayaan masyarakat merupakan suatu upaya dalam peningkatan kemampuan masyarakat guna mengangkat harkat hidup, martabat dan derajat kesehatannya. Peningkatan keberdayaan berarti peningkatan kemampuan dan kemandirian masyarakat agar dapat mengembangkan diri dan memperkuat sumber daya yang dimiliki untuk mencapai kemajuan (Direktorat Kesehatan dan Gizi Masyarakat, 2011)

Pemberdayaan masyarakat ditujukan untuk meningkatkan kesadaran, kemauan, dan kemampuan hidup masyarakat yang setinggitingginya, sebagai investasi bagi pembangunan SDM. Setiap orang berkewajiban ikut mewujudkan, mempertahankan dan meningkatkan derajat kesehatan masyarakat setinggi tingginya. Pemberdayaan masyarakat merupakan sasaran utama dari promosi kesehatan dan unsur penting yang tidak bisa diabaikan dalam rangka pencapaian kemandirian bidang kesehatan.

Masyarakat merupakan salah satu dari strategi global promosi kesehatan sehingga pemberdayaan masyarakat sangat penting untuk dilakukan agar masyarakat sebagai primary target memiliki kemauan dan kemampuan untuk memelihara dan meningkatkan kesehatan. Landasan hukum yang mengatur tentang kesehatan reproduksi dan $\mathrm{KB}$ di Indonesia tertuang dalam Undang-undang Nomor 36 Tahun 2009 tentang Kesehatan.

Dusun Pringgading adalah sebuah dusun yang terletak di wilayah Desa Guwosari Kecamatan Pajangan Kabupaten Bantul. Dusun Pringgading terbagi dalam dua wilayah yaitu Pringgading utara dan Pringgading selatan, walaupun terbagi dalam dua wilayah tetapi tetap dalam koordinasi satu pedukuhan. (Dusun Pringgading, no date). Di Dusun Pringgading Desa Guwosari Pajangan Bantul masih banyak pasangan usia subur yang menggunakan KB alamiah bahkan tidak menggunakan alat kontrasepsi. Masyarakat menganggap KB alamiah adalah cara menjaga kehamilan. Namun $\mathrm{KB}$ alamiah tidak cukup, karena bisa saja terjadi kegagalan jika salah dalam menghitung masa subur. Rendahnya pengetahuan atau informasi tentang penyakit kanker serta usaha pencegahan deteksi dini menyebabkan banyak wanita yang belum tertarik atau kurang berminat untuk melakukan usaha deteksi ini. Pembinaan Kesejahteraan Keluarga (PKK) merupakan organisasi masyarakat memberdayakan wanita untuk berpartisipasi dalam pembangunan Indonesia dengan salah satu program pokok di bidang kesehatan, sehingga anggota PKK dapat menjadi motor penggerak usaha peningkatan kesehatan keluarga di masyarakat terutama mengenai peningkatan pengetahuan $\mathrm{KB}$ dan deteksi dini kanker payudara (Yulinda and Fitriyah, 2018).

Orangtua terutama ibu merupakan salah satu hal terpenting dalam proses pendeteksian dini tumbuh kembang anak. Pada balita jika ada kelainan atau penyimpangan sekecil apapun, apabila tidak terdeteksi apalagi tidak tertangani dengan baik, maka akan mengurangi kualitas sumber daya manusia kelak di kemudian hari (Katharina and Iit, 2016). Pengetahuan orang tua sangat diperlukan agar orang tua dapat melakukan skrining untuk mendeteksi secara dini namun masih banyak banyak ibu yang belum paham akan skrining tumbuh kembang pada balita. Bahkan posyandu yang dilakukan setiap bulan di Dusun Pringgading belum pernah mengadakan skrining tentang tumbuh kembang menggunakan lembar KPSP. Berdasarkan masalah-masalah tersebut, solusi yang ditawarkan adalah melakukan pemberdayaan masyarakat dengan memberikan penyuluhan dan pemeriksaan sebagai bentuk promosi kesehatan sehingga dapat meningkatkan derajat kesehatan ibu dan anak.

\section{METODE}

Kegiatan PkM dilaksanakan di Dusun Pringgading Desa Guwosari Kecamatan Pajangan Kabupaten Bantul selama 2 minggu yaitu pada tanggal 07 - 18 Januari 2020. Tahap pertama adalah tahap persiapan berupa 
koordinasi tim. Adapun program gerakan pemberdayaan masyarakat sebagai berikut:

1. Program peningkatan kesehatan ibu dengan jumlah peserta 26 , meliputi kegiatan :

a. Penyuluhan pentingnya ber KB

b. Penyuluhan deteksi dini kanker payudara/ sadari

2. Program peningkatan kesehatan anak dengan jumlah peserta 35 , meliputi kegiatan:

a. Penimbangan balita

b. Pemeriksaan deteksi dini stimulasi pertumbuhan dan perkembangan balita

c. Penyuluhan pentingnya gizi balita

Kegiatan dilakukan dengan menggunakan media LCD, screen, pointer, powerpoint, dan menyusun poster, liflet, alat permainan edukatif, lembar balik. Adapun metode yang digunakan meliputi pendampingan ceramah, diskusi, dan demonstrasi.

\section{HASIL}

Pelaksanaan kegiatan pemberdayaan masyarakat sesuai dengan program yang direncanakan dengan mengakomodir permasalahan yang ada, terdiri dari berbagai macam kegiatan yang dapat menarik minat masyarakat sehingga masyarakat tidak bosan dan paham dengan materi yang disampaikan serta dapat diterapkan dalam kehidupan sehari hari.

Beberapa kegiatan yang telah diselenggarakan untuk meningkatkan kesehatan ibu seperti pada gambar sebagai berikut:
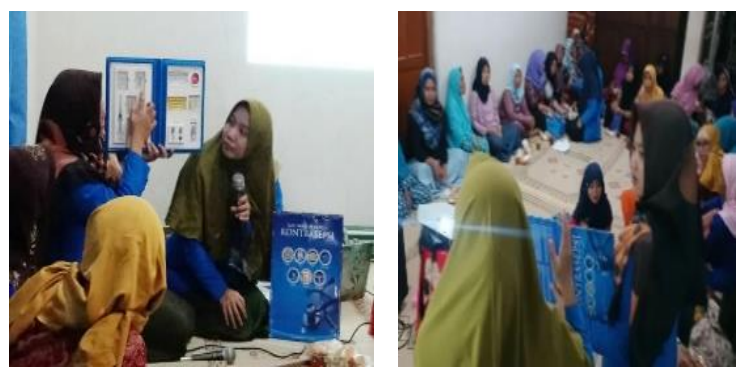

Gambar 1. Penyuluhan Pentingnya ber KB
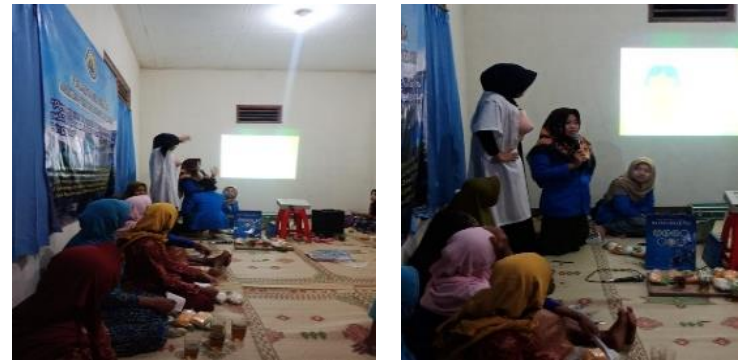

Gambar 2. Penyuluhan deteksi dini kanker payudara / sadari

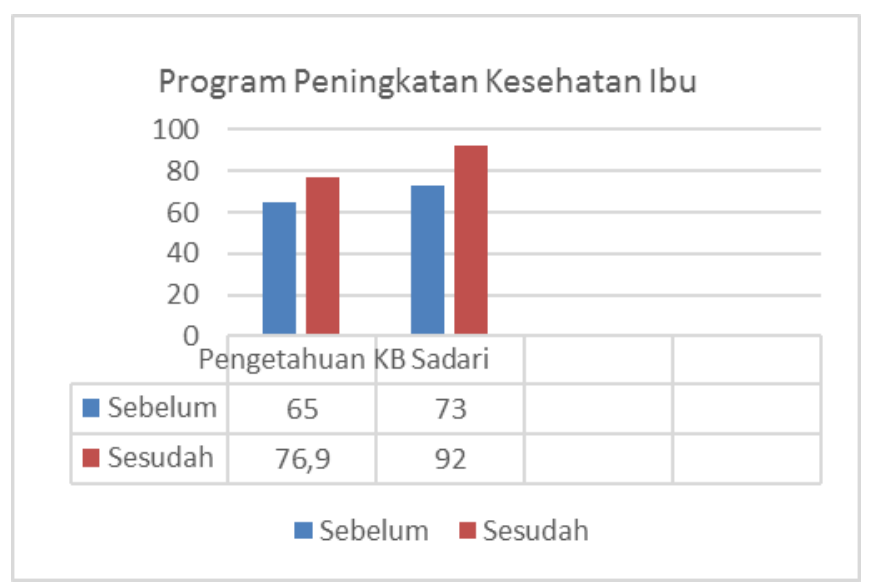

Gambar 3. Hasil pre test dan pos test pada program peningkatan kesehatan ibu.

Dari Gambar 3, dapat dilihat bahwa pada program peningkatan kesehatan anak meliputi kegiatan penyuluhan pentingnya ber KB dan penyuluhan deteksi dini kanker payudara / sadari dihadiri 26 peserta wanita usia subur. Penyuluhan pentingnya ber KB dilakukan dengan menggunakan media lembar balik sedangkan pada penyuluhan deteksi dini kanker payudara dilakukan dengan menggunakan media panthom payudara.

Sebelum dilakukan penyuluhan dilakukan pre test kemudian setelah dilakukan penyuluhan post test. Adapun hasilnya pada penyuluhan pentingnya ber $\mathrm{KB}$ nilai pretest sebesar $65 \%$ dan nilai posttest $76,9 \%$, Terjadi peningkatan sebesar $11,9 \%$. Sedangkan pada penyuluhan sadari nilai pretest sebesar $73 \%$ dan nilai posttest $92 \%$, Terjadi peningkatan sebesar $19 \%$.

Beberapa kegiatan yang telah diselenggarakan untuk meningkatkan kesehatan anak seperti pada gambar sebagai berikut: 


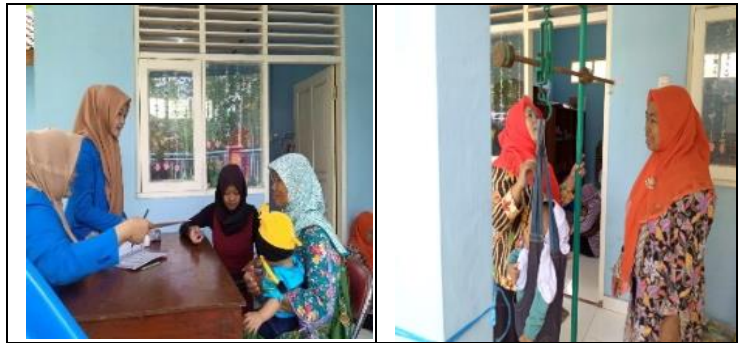

Gambar 4. Penimbangan balita

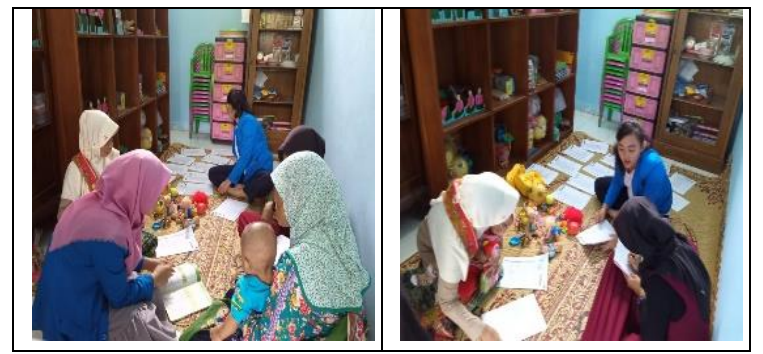

Gambar 5. Pemeriksaan deteksi dini stimulasi pertumbuhan dan perkembangan balita

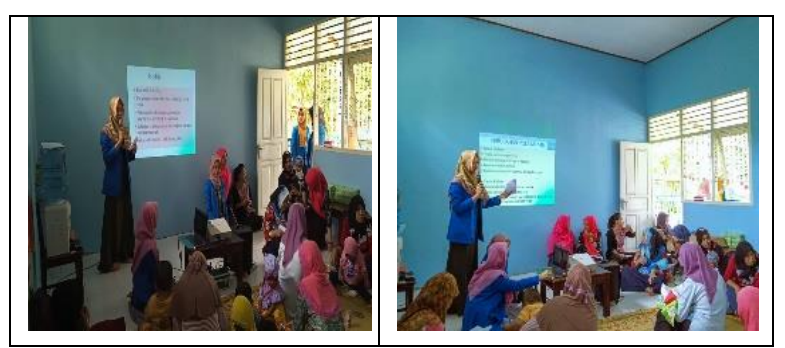

Gambar 6. Penyuluhan pentingnya gizi balita

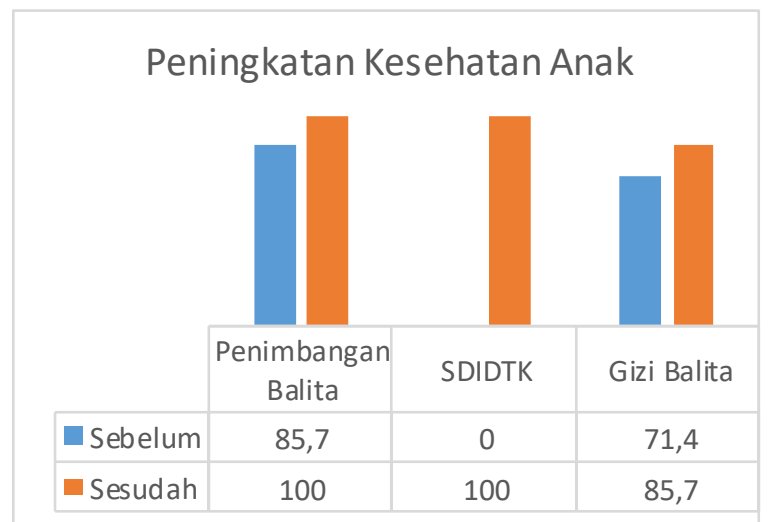

Gambar 7. Hasil pre test dan pos test pada program peningkatan kesehatan Anak.

Dari Gambar 7, dapat dilihat bahwa pada program peningkatan kesehatan anak meliputi kegiatan penimbangan balita, pemeriksaan deteksi dini stimulasi pertumbuhan dan perkembangan balita, penyuluhan pentingnya gizi balita dihadiri 35 peserta.

Adapun hasilnya pada kegiatan penimbangan balita yaitu data penimbangan balita sebelumnya dihadiri 30 balita kemudian pada saat kegiatan ini berlangsung penimbangan balita dihadiri oleh seluruh balita. Terjadi peningkatan sebesar 14,3\%. Sedangkan pada pemeriksaan deteksi dini stimulasi pertumbuhan dan perkembangan balita yaitu pada data sebelumnya belum pernah dilakukan kemudian pada saat kegiatan ini berlangsung dihadiri seluruh balita. Terjadi peningkatan sebesar $100 \%$. Sedangkan pada penyuluhan pentingnya gizi balita nilai pretest sebesar $71,4 \%$ dan nilai posttest $85,7 \%$, Terjadi peningkatan sebesar $16,1 \%$.

\section{PEMBAHASAN}

Pelaksanaan gerakan pemberdayaan masyarakat di Pringgading Desa Guwosari Kecamatan Pajangan Kabupaten Bantul menggunakan prinsip paradigma sehat dengan menjadikan masyarakat sebagai objek dan pelaku pembangunan (Budi Setyawan, 2012). Pada pelaksanaannya pemberdayaan masyarakat ini, tim pengabdi, kader berperan sebagai pendorong, motivator, penyuluh masyarakat dan menjadi jembatan antara petugas/ ahli kesehatan dengan masyarakat serta membantu masyarakat dalam mengidentifikasi dan menjawab kebutuhan kesehatannya (Kementrian Kesehatan Republik Indonesia, 2011; Widyo Subagyo, Mukhadiono, 2015).

Pada kegiatan untuk meningkatkan kesehatan ibu meliputi penyuluhan pentingnya ber $\mathrm{KB}$ dan penyuluhan deteksi dini kanker payudara/ sadari. Pada tanggal 13 Januari 2020, kami melakukan penyuluhan tentang Keluarga Berencana (KB) meliputi macam-macam alat kontrasepsi dan juga melakukan simulai pemeriksaan payudara sendiri (sadari). Diketahui bahwa di Dusun Pringgading sebagian besar menggunakan KB alami dan ada satu kasus benjolan pada payudara.

Pada saat kegiatan, ibu-ibu terlihat sangat antusias mendengarkan. Pada saat penyampaian langkah-langkah sadari pun ibuibu juga memperhatikan dengan seksama. Mereka juga mampu untuk mengulangi langkahlangkah sadari dengan sistematis. Pemeriksaan payudara sendiri dianjurkan dapat dilakukan sekali dalam satu bulan pada saat setelah menstruasi secara mandiri (Dahlan,F.M.,\& 
Ardhi, 2021). Penyuluhan tentang pemeriksaan payudara sendiri dapat meningkatkan pengetahuan dan wawasan seluruh wanita usia subur dengan tingkat pengetahuan dalam kategori baik (Perwiraningtyas and Trishinta, Sirli Mardianna, 2021).

Program kegiatan untuk meningkatkan kesehatan anak meliputi screening pemeriksaan tumbuh kembang dengan menggunakan KPSP dan penyuluhan stimulasi pertumbuhan dan perkembangan balita untuk deteksi dini pertumbuhan dan perkembangan balita sedangkan penyuluhan tentang pentingnya gizi pada balita untuk meningkatkan pengetahuan orangtua yang memiliki balita akan pentingnya kecukupan gizi pada anaknya. Kegiatan ini diadakan bersamaan dengan posyandu rutin di PAUD Dahlia Dusun Pringgading RT 04 pada 13 Januari 2020, pukul 09:00 - 12:00 WIB.

Screning pemeriksaan deteksi dini selain dapat mencegah terjadinya penyimpangan pertumbuhan, juga dapat mencegah terjadinya penyimpangan perkembangan dan penyimpangan mental emosional (Dinkes, 2014). Setelah dilakukan pemeriksaan dan penyuluhan pertumbuhan dan perkembangan didapatkan hasil di dusun pringgading masih ada balita yang pertumbuhan dan perkembangannya menyimpang dan balita kurang gizi. Kemudian dilakukan observasi dan stimulasi secara berkala penyebab dari menyimpangnya pertumbuhan dan perkembangan balita. Hasil evaluasi pertumbuhan dan perkembangan yaitu balita yang awalnya mengalami penyimpangan pertumbuhan dan perkembangan mendapatkan progress yang baik menjadi normal.

Setelah dilakukan penyuluhan tentang pentingnya kecukupan gizi bagi Balita didapatkan hasil penyebab utama dari balita kurang gizi karena kebanyakan balita tidak suka makan sayur. Dilakukan pendampingan pada keluarga yang memiliki balita gizi kurang dengan pendampingan cara mengolah variasi makanan pada balita agar balita tertarik pada makanan yang diberikan, didapatkan hasil ada peningkatan pengetahuan ibu dalam penyediaan makanan bervariasi dengan kecukupan gisi serta balita menjadi lebih tertarik untuk makan sesuai tahapan pertumbuhannya.

Penyuluhan merupakan kegiatan yang dapat menambah pengetahuan dan kemampuan seseorang melalui teknik belajar atau instruksi yang bertujuan mengubah atau mempengaruhi perilaku individu, kelompok atau masyarakat untuk dapat lebih mandiri dalam mencapai tujuan hidup sehat (Kemenkes RI., 2018). Kegiatan pemberdayaan masyarakat dapat meningkatan pengetahuan, sikap dan perilaku masyarakat dalam mengatasi permasalahan kesehatan di bidang kesehatan ibu dan anak sehingga dapat meningkatkan derajat kesehatan ibu dan anak di Dusun Pringgading Desa Guwosari Pajangan Bantul.

\section{KESIMPULAN}

Pemberdayaan Masyarakat meliputi program peningkatan kesehatan ibu dan program peningkatan kesehatan anak menjadi upaya strategis yang perlu terus dilanjutkan agar kampanye gerakan hidup sehat kepada masyarakat dapat terus berlanjut secara lebih masif dan sistemis. Melalui kegiatan ini, masyarakat tidak hanya menjadi objek namun juga sebagai subyek. Kegiatan yang terkait dengan upaya gerakan pemberdayaan masyarakat bidang kesehatan ibu dan anak yang dilakukan posyandu dan PKK, antara lain melakukan berbagai upaya untuk meningkatkan pengetahuan melalui penyuluhan pentingnya ber $\mathrm{KB}$, penyuluhan deteksi dini kanker payudara/ sadari, penyuluhan dan screening pemeriksaan deteksi dini pertumbuhan dan perkembangan balita, penyuluhan pentingnya gizi balita. pemberdayaan masyarakat tersebut dapat meningkatan pengetahuan, sikap dan perilaku masyarakat dalam mengatasi permasalahan kesehatan di bidang kesehatan ibu dan anak sehingga dapat meningkatkan derajat kesehatan ibu dan anak di Dusun Pringgading Desa Guwosari Pajangan Bantul.

\section{DAFTAR PUSTAKA}

Budi Setyawan, F. E. (2012) 'Paradigma Sehat', Jurnal Saintika Medika.

Dahlan,F.M.,\& Ardhi, Q. (2021) 'The Effect Of Fe Tablet And Date Palm On Improving Hemoglobin Level Among Pregnant Women In The Third Semester', Journal of Midwifery, 5(1), p. 32. doi: https://doi.org/10.25077/ jom.5.2.3238.2020 .

Direktorat Kesehatan dan Gizi Masyarakat (2011) 'Promosi kesehatan dan gizi masyarakat bidang kesehatan dan gizi masyarakat tahun 2010', Info Kajian BAPPENAS, 8(2), pp. 49-58. 
Dusun Pringgading (no date) https://mmprima. wordpress.com/letakpringgading/.

Katharina, T. and Iit, K. (2016) 'Hubungan Antara Pengetahuan Ibu Dengan Sikap Terhadap Tumbuh Kembang Anak Usia 024 Bulan', Jurnal Kebidanan, 6 (2), pp. 134-141.

Kemenkes RI. (2018) Profil Kesehatan Indonesia Tahun 2017. Jakarta: Kementerian Kesehatan RI.

Kementrian Kesehatan Republik Indonesia (2011) Kader kesehatan Posyandu Menuju Keluarga Sadar Gizi.

Perwiraningtyas, P. and Trishinta, Sirli Mardianna, S. (2021) 'Penyuluhan Kesehatan Sadari di Poli Obsgyn Rumah Sakit Panti Waluya Sawahan Malang', Lentera Jurnal, 1 (2), pp. 99-104.

Widyo Subagyo, Mukhadiono, D. W. (2015) 'Jurnal Keperawatan Soedirman (The Soedirman Journal of Nursing), Volume 10, No.3, November 2015', Jurnal Keperawatan Soedirman, 10 (3), pp. 158166.

Yulinda, A. and Fitriyah, N. (2018) 'Audiovusual Dalam Meningkatkan Pengetahuan Dan Sikap Tentang Sadari Di SMKN 5 Surabaya', Jurnal Promkes, 6 (2), pp. 116-128. 